\title{
IMPLEMENTASI TEKNIK POSSE DALAM PENGAJARAN PEMAHAMAN BACAAN PADA MAHASISWA PROGRAM STUDI PGSD UNIVERSITAS COKROAMINOTO PALOPO
}

\author{
MUSFIRAH \\ ${ }^{1}$ Universitas Cokroaminoto Palopo, J1. Latamacelling No.19 B, 047122111 \\ musfirahvire@gmail.com
}

\begin{abstract}
Abstrak
Penelitian ini bertujuan untuk mengetahui apakah teknik posse (Predicting, Arranging, Seaching, Summarizing, and Evaluation) ini efeketif atau tidak dalam pengajaran pemahaman bacaan pada Prodi PGSD Universitas Cokroaminoto Palopo. Metode penelitian ini yaitu pre experimental yang terdiri dari tiga tahapan, yakni: pre test, treatment dan post test dengan mengambil sampel sebanyak 20 orang mahamahasiswa pada program studi pendidikan bahasa inggris semester 2 menggunakan metode purposive sampling. Adapun instrument yang digunakan yakni berupa tes. Mahasiswa diberikan lembar kerja yang berisi bacaan da beberapa pertanyaan terkait dengan bacaan tersebut. Hasil dari penelitian ini menunjukkan bahwa penerapan teknik posse (predicting, arranging, searching, summarizing, and evaluation) efektif dalam mengajar dan meningkatkan pemahaman membaca mahasiswa pada cerita pendek. Pada pre test ditemukan pemahaman membaca mahasiswa nilai ratarata 49,75. Sedangkan pemahaman membaca mahasiswa pada post test dengan nilai rata-rata $76,45 \mathrm{Hal}$ ini menunjukkan bahwa pemahaman membaca mahasiswa lebih baik setelah dilakukan penerapan teknik posse ini
\end{abstract}

Kata Kunci:teknik posse, pemahaman bacaan

\begin{abstract}
This study aims to determine whether the posse technique (Predicting, Arranging, Searching, Summarizing, and Evaluation) is effective or not in teaching reading comprehension in Reading Compehension majors in primary school teacher education Cokroaminoto Palopo University. This research method is pre-experimental which consists of three stages, namely: pre-test, treatment and post-test by taking a sample of 20 second semester students by using purposive sampling method. The instrument used is in the form of a test. Students are given a worksheet containing readings and some questions related to the reading. The result of this study indicates that the application of posse techniques (predicting, arranging, searching, summarizing, and evaluation) is effective in teaching and improving students' reading comprehension in short stories. In the pre-test, it was found that students' reading comprehension had an average score of 49.75 . Meanwhile, the students' reading comprehension in the post test with an average value of 76.45. This shows that the students' reading comprehension is better after applying this posse technique.
\end{abstract}

Keywords: posse technique, reading comprehension 


\section{PENDAHULUAN}

Pemahaman bacaan adalah proses mental sadar dan tidak sadar yang kompleks di mana pembaca menggunakan berbagai strategi untuk merekonstruksi makna yang dianggap dimaksudkan oleh penulis, berdasarkan data dari teks dan dari pengetahuan awal pembaca (Latifah 2018) Pemahaman bacaan dianggap sebagai aspek penting bagi mahasiswa karena memberikan banyak informasi yang berguna, oleh karena itu mahasiswa perlu dilatih agar dapat memiliki pemahaman bacaan yang baik. Pemahaman bacaan juga merupakan kemampuan yang paling penting bagi pelajar EFL terutama dalam konteks akademik karena mahasiswa perlu memahami dan menangani semua aspek dan kesulitan membaca. Pemahaman bacaan (Tarbiyah and Ilmu 2017) bukanlah mata pelajaran yang sederhana dalam belajar bahasa Inggris, sulit untuk dikuasai. Ini masuk akal karena membaca melibatkan menentukan ide utama, mengidentifikasi informasi tertentu, referensi, kesimpulan dan kosa kata. Memiliki kemampuan membaca yang baik berarti pembaca memiliki kemampuan untuk memahami pernyataan tertulis atau jenis teks tertulis apa pun secara akurat dan efisien (Latifah 2018).

Pada Pembelajaran Bahasa Indonesia (Ika and Riana 2016), khususnya dalam pemahaman bacaan biasanya mahasiswa menghadapi banyak kesulitan, dan guru/dosen perlu menerapkan suatu teknik. Diperlukan suatu teknik untuk membuat proses pengajaran menjadi lebih efektif. Oleh karena itu, diperlukan strategi baru untuk meningkatkan pemahaman membaca mahasiswa untuk mengatasi permasalahan tersebut. Teknik posse merupakan salah satu teknik yang dapat membantu guru dalam memecahkan masalah mahasiswa dalam memahami materi bacaan. Pratama (Pratama 2018) menyatakan bahwa teknik dirancang untuk mengaktifkan pengetahuan mahasiswa sebelumnya dan menghubungkannya dengan yang baru dan strategi pembelajaran multi-langkah yang membantu mahasiswa untuk mengatur pengetahuan mereka dan meringkas dan menguraikan antara apa yang mereka ketahui dan apa yang telah mereka pelajari (Musfiqon and Nursyansyah 2015).

Teknik posse berarti Predicting atau memprediksi, (Dr. Meithiana Indrasari, S.T. 2017) Organizing atau mengatur, Searching atau mencari, Summarizing atau meringkas dan Evaluating atau mengevaluasi. Teknik ini dirancang untuk memodelkan kebiasaan membaca yang kuat kepada mahasiswa dan mengajari mereka bagaimana memanfaatkan strategi ini. Strategi pemahaman bacaan ini mencakup banyak praktik membaca yang telah terbukti 
membantu pemahaman bacaan, seperti pengorganisasian grafik, struktur teks, stimulasi pengetahuan latar belakang mahasiswa, dan pemantauan diri (Marlina 2017).

Berdasarkan informasi yang peneliti dapatkan dari dosen pengampu mata kuliah Pembelajaran Bahasa Indonesia pada Program Studi Pendidikan Guru Sekolah Dasar di Universitas Cokraminoto Palopo, nilai rata-rata prestasi mahasiswa dalam membaca bahasa Inggris rendah dan dipengaruhi oleh beberapa masalah. Pertama, mahasiswa mengalami kesulitan dalam memahami kata, frasa, dan kalimat bahasa indonesia. Kedua, mahasiswa mengalami kesulitan dalam menemukan ide pokok dari teks yang dibacanya (Ika and Riana 2016). Terakhir, mahasiswa mudah bosan membaca sebuah teks karena tidak menarik dan membuat mereka sulit memahami isi bahan bacaan. Oleh karena itu, berdasarkan masalah yang ditemukan di lokasi, peneliti melakukan penelitian yang berjudul implementasi teknik posse dalam pengajaran pemahaman bacaan pada mahasiswa program studi pendidikan Guru Sekolah Dasar di Universitas Cokroaminoto Palopo.

Adapun tujuan dari penelitian ini yakni ingin melihat apakah teknik posse ini efektif dalam pengajaran pemahaman bacaan (Teguh 2017). Kedepan, diharapkan hasil dari penelitian ini bisa berguna bagi dosen pengampu mata pelajaran tersebut untuk menjadi bahan acuan sehingga pembelajaran bisa lebih efektif, khususnya bagi mahamahasiswa agar beberapa kesulitan yang dihadapi bisa diatasi.

\section{METODE PENELITIAN}

Dalam penelitian ini, peneliti menggunakan metode penelitian pre experimental yang melibatkan sekelompok mahasiswa (Sugiono 2016). Penerapan metode ini dilakukan melalui beberapa tahap yakni, pre test, treatment dan post test. Pre test dilakukan untuk mengetahui kemampuan awal yang dimiliki oleh mahasiswa. Pada tahap ini, mahasiswa diberikan lembar kerja yang berupa beberapa bacaan dan beberapa pertanyaan terkait dengan bacaan yang ada di lembar kerja. Kemudian, pada tahap treatment, para mahasiswa diajarkan bagaimana memahami bacaan dengan baik dan peneliti juga menerapkan teknik posse ini. Tahap treatment dilakukan sebanyak lima kali pertemuan dalam kelas. Setelah beberapa kali treatment, maka peneliti kembali akan melakukan post test untuk mengetahui kemampuan akhir mahasiswa sekaligus mengetahui apakah teknik posse ini efektif dalam pengajaran pemahaman bacaan atau tidak. Post test dilakukan dengan cara kembali memberikan bacaan dan beberapa pertanyaan terkait dengan bacaan tersebut (Darusuprapti and Haryanto 2019). 
Sampel pada penelitian ini adalah para mahasiswa semester dua yang terdiri dari 20 orang mahasiswa dalam satu kelas yang sama. Peneliti menggunakan metode purposive sampling dalam memilih sampel. Adapun instumen dalam penelitian ini yaitu berupa pertanyaan pilihan ganda yang terdiri dari sepuluh pertanyaan.

\section{HASIL DAN PEMBAHASAN}

Tabel 1. Hasil pre test dan post test mahasiswa program studi PGSD UNCP

\begin{tabular}{cccc}
\hline No & Responden & Pre test & Post test \\
\hline 1 & Responden 1 & 50 & 78 \\
2 & Responden 2 & 50 & 80 \\
3 & Responden 3 & 40 & 68 \\
4 & Responden 4 & 60 & 80 \\
5 & Responden 5 & 60 & 85 \\
6 & Responden 6 & 35 & 68 \\
7 & Responden 7 & 35 & 65 \\
8 & Responden 8 & 35 & 75 \\
9 & Responden 9 & 60 & 75 \\
10 & Responden 10 & 55 & 85 \\
11 & Responden 11 & 60 & 75 \\
12 & Responden 12 & 35 & 65 \\
13 & Responden 13 & 48 & 78 \\
14 & Responden 14 & 50 & 78 \\
15 & Responden 15 & 57 & 78 \\
16 & Responden 16 & 50 & 75 \\
17 & Responden 17 & 40 & 78 \\
18 & Responden 18 & 45 & 78 \\
19 & Responden 19 & 65 & 80 \\
20 & Responden 20 & 65 & 85 \\
\hline & Total & 995 & 1529 \\
\hline & Mean Score & 49.75 & 76.45 \\
\hline & & & \\
19 & & 55 \\
\hline
\end{tabular}

Data di atas menunjukkan hasil penelitian ini yaitu pre-test dan post-test. 35 adalah nilai terendah pada pre test dan 65 adalah nilai tertinggi pada post test. 65 adalah nilai terendah pada post test dan 85 adalah nilai terbesar pada post test. Hasil di atas dirumuskan berdasarkan teknik analisis data dan nilai mahasiswa yang dikumpulkan melalui tes pemahaman bacaan. Dari tabel di atas dapat dikatakan bahwa banyak mahasiswa yang memiliki skor pemahaman membaca yang rendah dan dengan menerapkan teknik posse (predicting, arranger, searching, summarizing, and evaluation), dapat memperkaya 
pemahaman membaca mahasiswa pada cerita pendek. Sehingga dapat memacu nilai mahasiswa untuk lebih baik dalam post test.

Penelitian ini bertujuan untuk mengetahui efektivitas penerapan teknik pagar betis yang efektif dalam pembelajaran membaca pemahaman cerpen pada Program Studi Pendidikan guru Sekolah Dasar. Sejalan dengan temuan di atas, dapat disimpulkan bahwa pengajaran pemahaman membaca dengan menerapkan teknik posse (predicting, arranger, searching, summarizing, and evaluation)) meningkatkan pemahaman membaca mahasiswa pada cerita pendek. Hal ini dapat digambarkan nilai mahasiswa pada post test lebih baik dari pada pre test. Nilai rata-rata pada post test adalah 76,45 dan pada pre test adalah 49,75.

Penerapan teknik posse dalam melakukan treatment pada program studi pendidikan Guru Sekolah Dasar, peneliti memfokuskan pada lima langkah. Langkah pertama adalah memprediksi, peneliti menggunakan kegiatan brainstorming untuk mengaktifkan latar belakang pengetahuan mahasiswa, dengan menggunakan petunjuk dari teks seperti judul, judul, gambar, dan beberapa baris dari paragraf. Langkah kedua adalah pengorganisasian. Peneliti meminta mahasiswa untuk mengorganisasikan ide-ide mereka yang telah mereka prediksi pada tahap pertama dalam kategori-kategori seperti yang disebutkan dalam lembar kerja. Langkah ketiga adalah mencari. Peneliti meminta mahasiswa membaca teks dalam hati untuk mengidentifikasi gagasan utama setiap paragraf, dan mencari kosa kata baru, dan informasi asing dan kemudian menuliskannya pada lembar kerja. Langkah keempat adalah meringkas. Peneliti mengarahkan mahasiswa untuk meringkas teks yang disajikan dalam lembar kerja. Langkah kelima adalah mengevaluasi. Pada langkah ini, peneliti mengarahkan mahasiswa untuk menjawab pertanyaan pemahaman berdasarkan ringkasan teks.

Sebelum menerapkan teknik posse, peneliti menemukan beberapa mahasiswa kesulitan menjawab soal pre test. Mahasiswa tidak dapat menulis jawaban dengan baik karena mereka tidak memahami isi teks. Namun setelah dilakukan perlakuan dengan teknik pagar betis mahasiswa lebih baik dalam menjawab soal yang diberikan oleh peneliti. Dalam menunjukkan bahwa teknik posse diyakini dapat meningkatkan pemahaman membaca mahasiswa pada cerita pendek. Sebelumnya, mahasiswa menemukan banyak kesulitan dalam memahami teks. Mereka membaca teks dengan menerjemahkan setiap kata dalam teks. Sekarang, mereka bisa memahami teks melalui teknik posse. Meskipun pada awalnya mereka bingung untuk menerapkan teknik tersebut, pada saat kedua mereka mengakui bahwa teknik 
posse dapat membantu mereka memahami teks dengan lebih baik. Hal ini juga dapat mendorong membaca mahasiswa secara strategis seperti memprediksi teks, mengatur prediksi, mencari ide-ide utama dari setiap paragraf, meringkas teks, dan mengevaluasi pemahaman mereka.

Peneliti juga menemukan bahwa teknik posse diyakini dapat meningkatkan partisipasi mahasiswa terhadap proses belajar mengajar pemahaman bacaan. Selama penerapan strategi, mahasiswa didorong untuk aktif dalam memberikan ide-ide mereka. Mereka mendiskusikan bacaan mereka dan menggunakan strategi memprediksi, mengatur, mencari, meringkas, dan mengevaluasi untuk memahami teks.

Fenomena lain ketika peneliti melakukan treatment, ditemukan teknik posse dapat meningkatkan interaksi di kelas. Kegiatan teknik ini dilakukan secara berkelompok. Kegiatan ini memungkinkan mahasiswa untuk berinteraksi dengan teman sekelas mereka. Hal ini juga meningkatkan interaksi antara dosen dan mahasiswa. Dosen berinteraksi erat dengan mahasiswa ketika memberikan bimbingan dan bantuan selama kegiatan diskusi.

\section{SIMPULAN DAN SARAN}

Berdasarkan hasil temuan dan diskusi, dapat disimpulkan bahwa pengajaran dengan penerapan teknik posse (predicting, arranging, searching, summarizing, and evaluation) efektif dalam mengajar dan meningkatkan pemahaman membaca mahasiswa pada cerita pendek. Pada pre test ditemukan pemahaman membaca mahasiswa nilai rata-rata 49,75. Sedangkan pemahaman membaca mahasiswa pada post test dengan nilai rata-rata $76,45 \mathrm{Hal}$ ini menunjukkan bahwa pemahaman membaca mahasiswa lebih baik setelah dilakukan treatment. 


\section{DAFTAR PUSTAKA}

Darusuprapti, Fajarsih, and Haryanto Haryanto. 2019. "Peningkatan Keterampilan Menulis Cerita Pendek Menggunakan Media Pembelajaran Pop-Up.” Widyaparwa 47(1): 69-79.

Dr. Meithiana Indrasari, S.T., M.M. Kepuasan. 2017. "Kepuasan Kerja Dan Kinerja Karyawan Tinjauan Dari Dimensi Iklim Organisasi , Kreatifitas Individu, Dan Karakteristik Pekerjaan." Yogyakarta: Indomedia Pustaka: 1-85.

Ika, Mustika, and Dwi Lestari Riana. 2016. "Hubungan Minat Baca Dan Kebiasaan Membaca Karya Sastra Terhadap Kemampuan Menulis Puisi." Jurnal Semantik STKIP Siliwangi 5(2): 15-31. http://www.ejournal.stkipsiliwangi.ac.id/index.php/semantik/article/view/291/221.

Latifah, Nur. 2018. Mengembangkan Kompetensi Pendidik dalam Menghadapi Era Disrupsi" Kerjasama PGSD - POR UMS BAHASA INDONESIA.

Marlina, Lona. 2017. "Pengembangan Desain Pembelajaran Bahasa Inggris Berbasis ELearning." (1).

Musfiqon, and Nursyansyah. 2015. Pendekatan Pembelajaran Saintifik. Nurdyansya. Sidoarjo: Nizamia Learning Center Sidoarjo.

Pratama, Afis. 2018. "Pengaruh Pengajaran Pemrogaman Animasi Melalui Aplikasi Scratch Pada Kemampuan Pemecahan Masalah.” Joined Journal (Journal of Informatics Education) 1(1): 24.

Sugiono. 2016. METODE PENELITIAN (Kuantitatif, Kualitatif, Dan R\&D. 1st ed. Bandung: Alfabeta CV.

Tarbiyah, Fakultas, and Dan Ilmu. 2017. "Melalui Strategi Pembelajaran.” peningkatan pemahaman konsep matematika.

Teguh, Mulyo. 2017. “Gerakan Literasi Sekolah Dasar.” Prosiding Seminar Nasional 2(1): $18-26$. 